\title{
Polar cap flow channel events: spontaneous and driven responses
}

\author{
P. E. Sandholt ${ }^{1}$, Y. Andalsvik ${ }^{1}$, and C. J. Farrugia ${ }^{2}$ \\ ${ }^{1}$ Department of Physics, University of Oslo, Oslo, Norway \\ ${ }^{2}$ Space Science Center, University of New Hampshire, Durham, USA
}

Received: 19 May 2010 - Revised: 26 August 2010 - Accepted: 27 October 2010 - Published: 5 November 2010

\begin{abstract}
We present two case studies of specific flow channel events appearing at the dusk and/or dawn polar cap boundary during passage at Earth of interplanetary (IP) coronal mass ejections (ICMEs) on 10 January and 25 July 2004. The channels of enhanced $(>1 \mathrm{~km} / \mathrm{s})$ antisunward convection are documented by SuperDARN radars and dawn-dusk crossings of the polar cap by the DMSP F13 satellite. The relationship with Birkeland currents $(\mathrm{C} 1-\mathrm{C} 2)$ located poleward of the traditional R1-R2 currents is demonstrated. The convection events are manifest in ground magnetic deflections obtained from the IMAGE (International Monitor for Auroral Geomagnetic Effects) Svalbard chain of ground magnetometer stations located within $71-76^{\circ}$ MLAT. By combining the ionospheric convection data and the ground magnetograms we are able to study the temporal behaviour of the convection events. In the two ICME case studies the convection events belong to two different categories, i.e., directly driven and spontaneous events. In the 10 January case two sharp southward turnings of the ICME magnetic field excited corresponding convection events as detected by IMAGE and SuperDARN. We use this case to determine the ground magnetic signature of enhanced flow channel events (the NHdusk $/ B_{\mathrm{y}}<0$ variant). In the 25 July case a several-hour-long interval of steady southwest ICME field $\left(B_{\mathrm{z}}<0 ; B_{\mathrm{y}}<0\right)$ gave rise to a long series of spontaneous convection events as detected by IMAGE when the ground stations swept through the 12:00-18:00 MLT sector. From the ground-satellite conjunction on 25 July we infer the pulsed nature of the polar cap ionospheric flow channel events in this case. The typical duration of these convection enhancements in the polar cap is $10 \mathrm{~min}$.
\end{abstract}

Keywords. Ionosphere (Plasma convection) - Magnetospheric physics (Polar cap phenomena; Solar windmagnetosphere interactions)

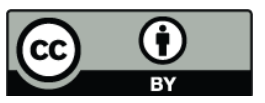

Correspondence to: P. E. Sandholt (p.e.sandholt@fys.uio.no)

\section{Introduction}

In previous studies we documented the presence of a channel of enhanced (1-3 km/s) antisunward ionospheric convection appearing at the dawn and/or dusk sides of the polar cap, its location depending on the IMF orientation (see Sandholt and Farrugia, 2009, and references therein). When sorted by hemisphere (north or south), side of the polar cap (dawn and/or dusk), IMF $B_{\mathrm{y}}$ polarity, and clock angle range, five convection configurations in the polar cap involving this flow feature, which we call FC 2, have been identified: (i) $\mathrm{NH}$ dawn $/ B_{\mathrm{y}}>0$, (ii) $\mathrm{SH}-$ dusk $/ B_{\mathrm{y}}>0$, (iii) $\mathrm{NH}$-dusk $/ B_{\mathrm{y}}<0$, (iv) $\mathrm{SH}$-dawn $/ B_{\mathrm{y}}<0$, and (v) (dawn + dusk) $/ B_{\mathrm{Z}}$-dominated $\left(\left|B_{\mathrm{y}}\right| /\left|B_{\mathrm{z}}\right|<1\right.$; clock angle $\left.>135^{\circ}\right)$.

This category of flow channel should be distinguished from the flow excited in association with newly open magnetic field lines (called here FC 1) and which is accompanied by dynamic auroral emissions in the cusp region (see e.g. Sandholt et al., 1990; Pinnock et al., 1993, and Provan et al., 1999). The flow channel we call FC 2 is observed on the downstream side of the cusp, accompanied by polar rain precipitation. Key FC 2 properties are: (i) a $\sim 200$ $300 \mathrm{~km}$ wide channel of enhanced antisunward flow (ion drift speeds larger than in the central polar cap) located immediately poleward of the oval aurora (plasma sheet precipitation) at 06:00-09:00/15:00-18:00 MLTs, (ii) in association with a system of outward-inward directed Birkeland currents located poleward of the traditional R1-R2 currents via their Pedersen current closure in the ionosphere.

In Sandholt et al. (2010) we reported one case showing the presence of a series of 5-10-min-long negative X-component magnetic deflections detected at ground stations located underneath the FC 2 flow channel of type NH-dusk $/ B_{\mathrm{y}}<0$. This led us to speculate that the ionospheric ion flow was also pulsed in this case and possibly related to flux transfer events (FTEs), i.e., momentum transfer in a later stage of the evolution of field lines previously opened by pulsed magnetopause reconnection. In an earlier paper we also discussed

Published by Copernicus Publications on behalf of the European Geosciences Union. 
this possibility from a different perspective, i.e., high-altitude magnetospheric plasma and magnetic field observations from Cluster (Farrugia et al., 2004). In the present study we shall explore the temporal variability of flow channel FC 2 (NHdusk $/ B_{\mathrm{y}}<0$ ) from the ionospheric perspective further. The following approach is adopted. We selected two categories of events: (i) those "directly driven" by southward turnings of the interplanetary magnetic field (IMF), i.e., the IMF turns south and, after an appropriate time delay for propagation, the flow channel is observed; (ii) "spontaneous" events occurring during periods of stable southward-directed magnetic field outside the magnetosphere, i.e., IMF $B_{\mathrm{z}}$ is uninterruptedly negative for a long time spell, and during this time the flow channel is intermittently excited. From category (i) we determine the correspondence between discrete convection enhancements (Greenwald et al., 1999) and ground magnetic deflections at magnetometer stations in the polar cap. Then we shall apply this information to document the presence of a series of $\sim 10$-min-long convection enhancements during intervals of quasi-stable magnetic field conditions in interplanetary coronal mass ejections (ICME) at the time of their Earth passage (the "spontaneous events"; see e.g. Sandholt and Farrugia, 2006). Intervals of ICME passage at Earth were selected because of the strong and ordered forcing of the magnetosphere which occur in such cases (Burlaga et al., 1981; Farrugia et al., 1998).

Magnetograms from the high-latitude $\left(71-76^{\circ}\right.$ MLAT) magnetometer stations on Svalbard (IMAGE chain; http: //www.geo.fmi.fi/image) are combined with ionospheric ion drift observations in the same magnetic local time - magnetic latitude (MLT/MLAT) sector obtained by ground-based radars of the SuperDARN network (Greenwald et al., 1995) and from satellite DMSP F13 (see e.g. Hairston et al., 1998). By using ground - satellite conjunctions we are able to document the different ion drift signatures observed in the different phases (maximum and recovery) of the ground magnetic deflection events. In this way we are able to establish the detailed correspondence between the temporal evolution of the ionospheric ion drift events in flow channel FC 2 and the magnetic deflections detected at ground stations underneath the ionospheric flow feature. Thus, we shall take advantage of the ability of continuous ground observations of magnetic deflections to monitor the temporal variability of ionospheric Hall currents.

\section{Data description}

As indicated already in the title of the paper we report two categories of events, i.e., those "directly driven" by southward turnings of the external magnetic field (IMF or the ICME field during Earth passage) and those occurring during steady external field conditions (the "spontaneous" events). In case 1 (10 January 2004) we shall focus on "directly driven" events, which was observed when the magnetic field
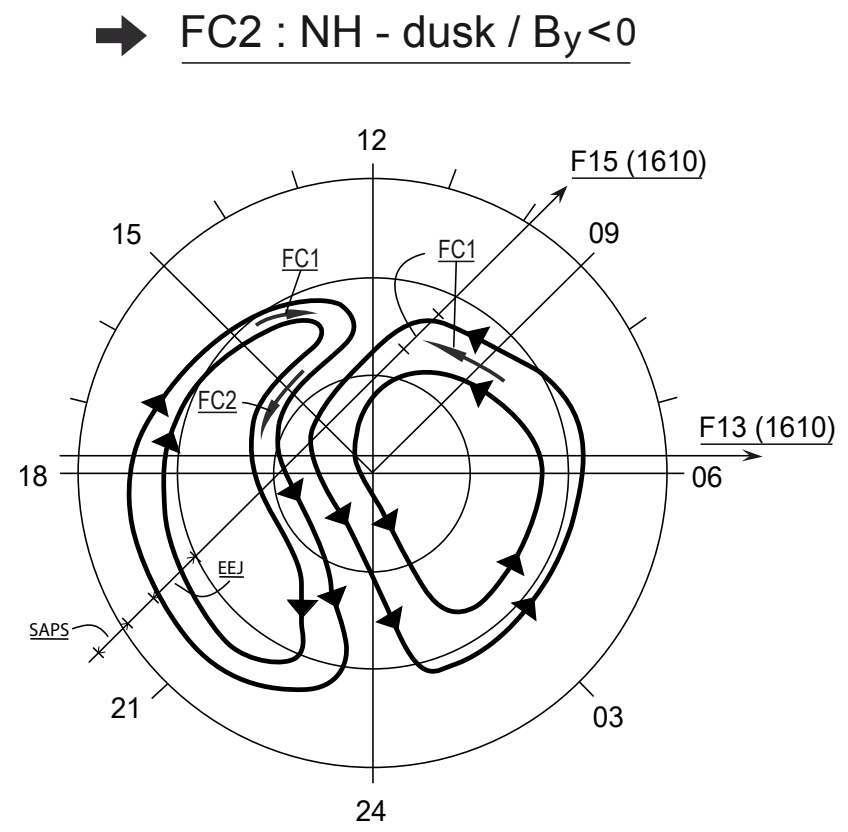

Fig. 1. Flow channel FC 2 (bold arrow) in the context of Dungey convection cells (flow lines) and flow channels FC 1 representing southwest $\left(B_{\mathrm{Z}}<0 ; B_{\mathrm{y}}<0 ;\left|B_{\mathrm{Z}} / B_{\mathrm{y}}\right|<1\right)$ IMF conditions. (Adapted after Fig. 2 in Greenwald et al., 2002). Trajectories of satellites DMSP F13 and F15 which crossed through flow channels FC 2 and FC 1, respectively, have been marked in the figure.

of the ICME was southwest-directed $\left(B_{\mathrm{z}}<0 ; B_{\mathrm{y}}<0\right)$ and $B_{\mathrm{y}}$-dominated $\left(\left|B_{\mathrm{z}} / B_{\mathrm{y}}\right|<1\right)$. In the second case (25 July 2004) we report "spontaneous" events when the magnetic field of the ICME was southwest-directed $\left(B_{\mathrm{z}}<0 ; B_{\mathrm{y}}<0\right)$ and $B_{\mathrm{z}}$-dominated $\left(\left|B_{\mathrm{z}} / B_{\mathrm{y}}\right|>1\right)$.

\subsection{Background on FC 2 of type NH-dusk $/ B_{\mathrm{y}}<0$}

In our case 1 we shall discuss the variant of flow channel FC 2 which is found on old open field lines in the dusk side convection cell of the Northern Hemisphere during negative IMF $B_{\mathrm{y}}$ conditions, which we refer to as NH-dusk $/ B_{\mathrm{y}}<$ 0 (Sandholt and Farrugia, 2009). Figure 1 is an introduction to this convection feature schematically placed in the context of the Dungey convection cells. Flow channels FC 1 and FC 2 have been marked by bold arrows in the sectors of the convection cells they lie in. This figure refers to the IMF conditions discussed in case 1 of this paper (southwestdirected: $\left.B_{\mathrm{Z}}<0 ; B_{\mathrm{y}}<0 ;\left|B_{\mathrm{Z}} / B_{\mathrm{y}}\right|<1\right)$. The flow lines drawn in this figure is an extract of the traditional convection pattern as inferred from SuperDARN radar observations during an extended 5-h interval of quasi-stationary southwest-directed $\left(B_{\mathrm{z}}<0 ; B_{\mathrm{y}}<0\right)$ IMF orientation on 16 December 1997 (see Fig. 2 in Greenwald et al. (2002)). Below we shall discuss the spatial-temporal structure of the $\mathrm{NH}$-dusk $/ B_{\mathrm{y}}<0$ variant of FC 2 based on combined SuperDARN and ground magnetic observations on 10 January 2004. 


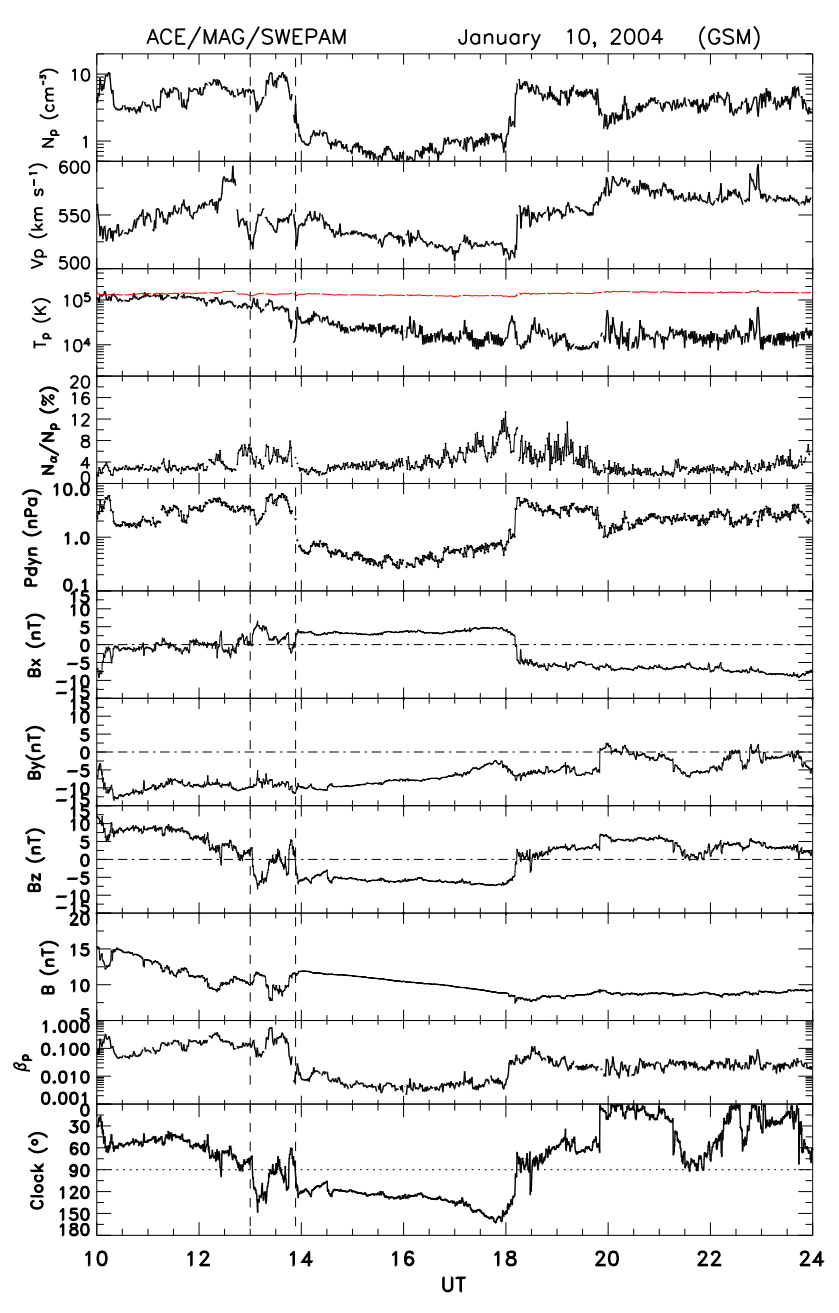

Fig. 2. Interplanetary plasma and field data obtained from spacecraft ACE during the interval 10:00-24:00 UT on 10 January 2004: proton density, bulk speed, and temperature (in red: expected temperatures for normal solar wind expansion after Lopez, 1986), the alpha-particle-to-proton number density ratios, the dynamic pressure, the components of the magnetic field in GSM coordinates, and the total field strength, the proton plasma beta and the clock angle of the magnetic field.

On 10 January 2004 (our case) the presence of flow channel FC 1 in the morning cell as well as the indicated flow characteristics of the dusk cell (in the 20:00-21:00 MLT sector) are documented by ion drift data obtained during a passage of satellite DMSP F15 from pre-midnight to pre-noon (as marked in the figure) in the interval 15:57-16:27 UT (data not shown). The dusk-to-dawn crossing of satellite DMSP F13 also marked in the figure documented the presence of flow channel FC 2 (data not shown).

\subsection{Case 1: 10 January 2004 ("directly driven" response)}

For the interval 10:00-24:00 UT, Fig. 2 shows solar wind and magnetic field data obtained by the ACE spacecraft on 10 January 2004. From top to bottom, the panels show the proton density, bulk speed, and temperature (in red: expected temperature after Lopez and Freeman, 1986), the alphaparticle-to-proton number density ratios, the dynamic pressure, the components of the magnetic field in GSM coordinates, and the total field strength, the proton plasma beta and the clock angle of the magnetic field (i.e., the polar angle in the GSM $Y Z$ plane). The expected temperature in panel 3 was derived by Lopez and Freeman (1986) (see also Lopez, 1987) from a statistical examination of Helios 1 data which resulted in a relationship between the temperature $(T)$ and velocity $(V)$ of the solar wind.

During the interval studied, ACE was orbiting the lagrangian L1 point. Its average distance from the Sun-Earth line is $\sim 43 R_{\mathrm{E}}$. Studies on the correlation length of IMF and solar wind parameters give a correlation length of order 40$70 R_{\mathrm{E}}$ in the Y-direction (Crooker et al., 1982; Richardson and Paularena, 2001). However, for ICMEs the correlation lengths extend to at least $200 R_{\mathrm{E}}$ (Farrugia et al., 2005). So the measurements at ACE should give the parameters affecting the magnetosphere, when properly time lagged.

We shall focus on the interval 13:00-18:00 UT, representing the leading edge of the magnetic cloud and note the following features: (i) sharp southward turnings of the magnetic field at 13:00 and 13:50 UT (vertical guidelines), (ii) stable south-west ( $B_{\mathrm{z}}=-4$ to $-5 \mathrm{nT} ; B_{\mathrm{y}}=-7$ to $-10 \mathrm{nT}$ ) directed field during the rest of the interval (clock angle increasing from 120 to $\left.160^{\circ}\right)$, (iii) low plasma density $\left(\sim 1 \mathrm{~cm}^{-3}\right)$ and dynamic pressure $(<1 \mathrm{nPa})$ during the sub-interval 14:0018:00 UT. At 10:00 UT ACE is at $(233,-37,220) R_{\mathrm{E}}$. With a convection speed of $\sim 525 \mathrm{~km} / \mathrm{s}$, we estimate a delay of $\sim 47$ min for the IP disturbances to reach the subsolar magnetopause. To this must be added a few minutes to account of (1) the slower propoagation speed in the magnetosheath and (2) intrinsic response times of the magnetosphere-ionosphere system.

Figure 3 shows IMAGE (International Monitor for Auroral Geomagnetic Effects) magnetograms from four stations on Svalbard when these stations swept through the 16:0020:00 MLT sector. We note the following features: (i) Onsets of convection bays $(\delta H<0)$ appearing at 14:00 and 14:50 UT. (ii) Recovery after the first convection bay during 14:20-14:50 UT. (iii) A third convection enhancement appeared at 15:50 UT. (iv) While the 14:00 UT event (maximum phase in the interval 14:08-14:15 UT) appears clearly in the Ny Ålesund (NAL)-Longearbyen(LYR)-Hornsund (HOR) (76-73 ${ }^{\circ}$ MLAT) station records, it is absent in the Bear Island (BJN; 71 ${ }^{\circ}$ MLAT) magnetogram. By contrast, the events at 14:50 and 15:50 UT are also manifest in the data obtained at the southernmost station BJN. 


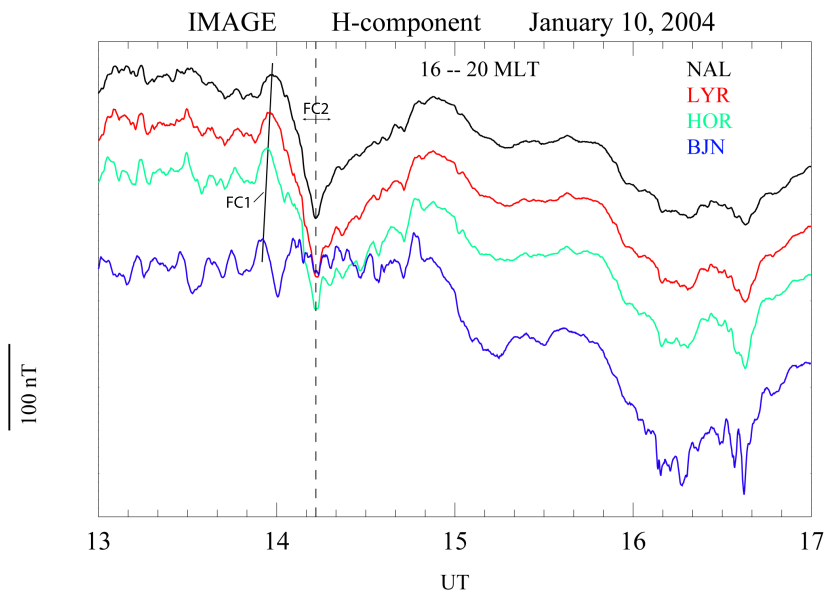

Fig. 3. H-component magnetograms from the IMAGE Svalbard chain of stations during the interval 13:00-17:00 UT. Panels from top to bottom shows magnetograms from stations NAL $\left(76^{\circ}\right.$ MLAT; black trace), LYR ( $75^{\circ}$ MLAT; red), HOR ( $74^{\circ}$ MLAT; green), and BJN $\left(71^{\circ}\right.$; blue). The vertical guideline at $14: 12$ UT marks the time of observation by SuperDARN radars of flow channel FC 2 (NHdusk $\left./ B_{\mathrm{y}}<0\right)$ above Svalbard, representing the maximum phase (14:08-14:15 UT) of the magnetic deflection/convection event. The FC 2 event is marked in the figure. The positive H-deflections propagating poleward from BJA to NAL during the interval 13:50 14:00 UT are also marked. This feature corresponds to the activation of flow channel FC 1 (see Fig. 1).

By comparison with the ACE plot in Fig. 2 we identify the convection bays initiated at $\sim 14: 00$ UT and 14:50 UT as "directly driven" by the two sharp southward turnings of the magnetic field recorded by ACE at 13:00 and 13:50 UT. It is well known that such southward turnings of the IMF give rise to convection enhancements (Greenwald et al., 1999).

Next we shall show a spatial plot of plasma convection in the postnoon sector (including the Svalbard area) as obtained by SuperDARN radars in Finland, Iceland and Canada at 14:10-14:12 UT, representing the maximum phase of the magnetic deflection event. This allows us to relate the ground magnetic deflections shown in Fig. 3 to the local plasma convection configuration. In this way we shall demonstrate the association between the negative $\mathrm{H}$-deflection during the interval 14:08-14:15 UT (maximum phase) and the enhanced antisunward flow in the FC 2 channel as indicated in Fig. 4. The poleward propagating positive deflection occurring ahead of the negative excursion (observed during the interval 13:50-14:00 UT) reflects the activation of flow channel FC 1 (see the schematic illustration in Fig. 1). This flow feature (FC 1 event) is accompanied by poleward moving auroral forms (PMAFs), as demonstrated in Sandholt et al. (1990) and Øieroset et al. (1997).

Figure 4 shows a spatial plot of plasma convection recorded during the 2-min scan from 14:10-14:12 UT. We shall focus on the convection pattern in the postnoon sector

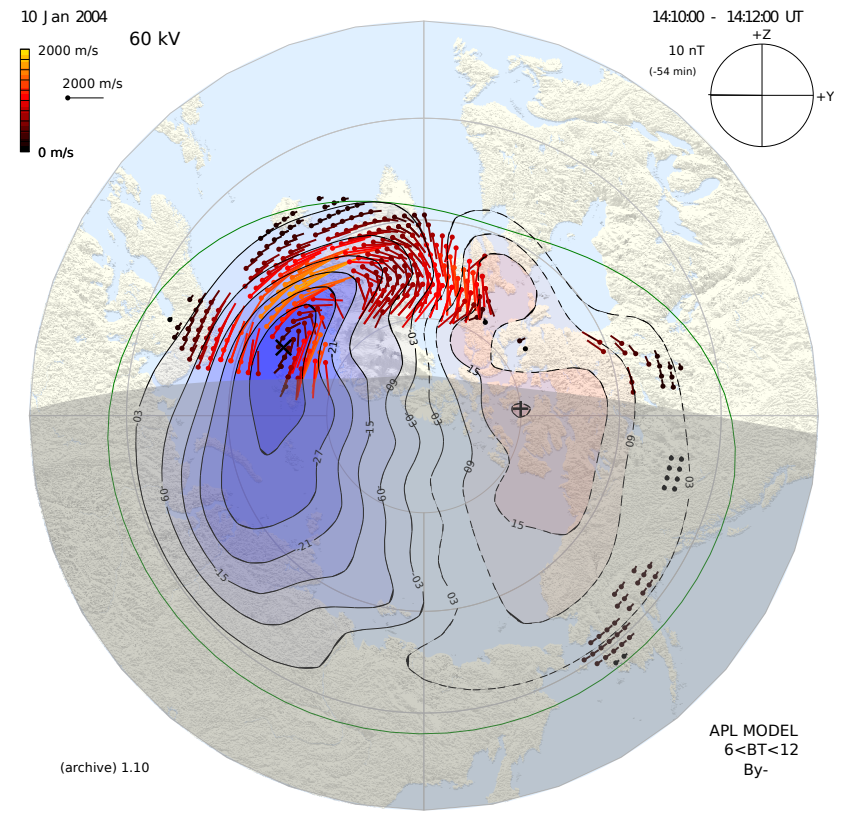

Fig. 4. Spatial plot of plasma convection obtained by SuperDARN radars during the 2-min scan at 14:10-14:12 UT. The coordinate system is MLT/MLAT. The terminator is marked in the figure.

(to the left) consisting of a crescent-shaped cell, as is appropriate for the prevailing southwest-directed magnetic field detected by ACE. A channel of $\geq 1 \mathrm{~km} / \mathrm{s}$ antisunward convection is seen in the 15:00-17:00 MLT/75-78 MLAT sector. This is our flow channel FC 2 . It is the convection response to the first southward turning (detected by ACE at 13:00 UT) and the cause, through the associated Hall currents, of the the negative $\mathrm{H}$-component magnetic deflections detected at the Svalbard ground stations HOR-LYR-NAL (74-76 ${ }^{\circ}$ MLAT) beneath the flow channel as documented in Fig. 3. The flow channel is located in a sector with sunlit ionosphere (see the terminator location). From Figs. 2, 3 and 4 we may infer a 15 min long (14:05-14:20 UT) FC 2 convection event which is "directly driven" by the south-west directed ICME magnetic field detected by ACE during the interval 13:0513:20 UT.

\subsection{Background on FC 2 of type NH-(dawn + dusk)/ $B_{\mathrm{z}}$-dominated}

Figure 5 is an introduction to our case 2 observations illustrating the average (background) convection pattern (the flow lines) at 10:40 (top panel) and 12:20 UT on 25 July 2004 corresponding to the prevailing ICME magnetic field conditions ( $B_{\mathrm{Z}}$-dominated), according to the APL-model as described by Ruohoniemi and Baker (1998).

The two DMSP F13 passes discussed in this case have been marked in the figure. We also added bold arrows to indicate the position of flow channels FC 2 as detected by DMSP F13 during these passes, i.e., on the dusk side at 10:42 UT 


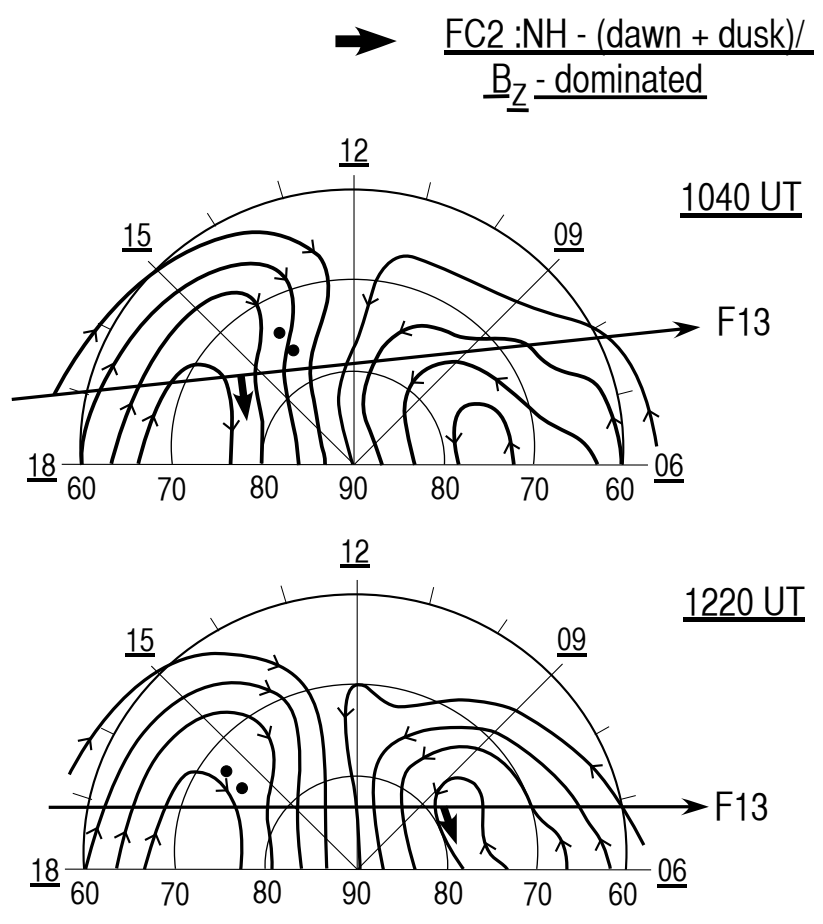

Fig. 5. Averaged convection patterns at 10:40 UT (top panel) and at 12:20 UT (bottom) on 25 July 2004 corresponding to the ICME magnetic field conditions observed by Wind, according to the APLmodel (see Ruohoniemi and Baker, 1998). Marked by solid dots are two magnetometer stations on Svalbard (NAL-HOR). Marked by arrowed lines are DMSP F13 passes during the intervals 10:3011:00 UT and 12:11-12:41 UT.

(top panel) and on the dawn side at 12:30 UT. The variant of FC 2 observed on this day (present on both sides of the polar cap during $\left|B_{\mathrm{z}} / B_{\mathrm{y}}\right|>1$ conditions) is that we refer to as FC 2 of type NH-(dawn + dusk $) / B_{\mathrm{Z}}$-dominated.

\subsection{Case 2: 25 July 2004 ("spontaneous" response)}

Figure 6 shows plasma and magnetic field data obtained from spacecraft Wind during the interval 08:00-16:00 UT on 25 July 2004. The format is the same as that of Fig. 2. The average Wind location was $(261,-1,18) R_{\mathrm{E}}$ (GSE coordinates). We shall direct attention to the relatively stable magnetic field conditions prevailing during the interval 08:00-15:00 UT, despite the field and flow discontinuity at $\sim 12$ :00 UT. The field is strong (15-25 nT), directed southwest $\left(B_{\mathrm{z}}=-10\right.$ to $-20 \mathrm{nT} ; B_{\mathrm{y}}=-10$ to $\left.-20 \mathrm{nT}\right)$. The clock angle varies slowly between $120-160^{\circ}$. The speed is high (within $500-700 \mathrm{~km} / \mathrm{s}$ ), while the plasma density changes between low values $\left(1-2 \mathrm{~cm}^{-3}\right)$ during 08:00-12:00 UT and higher values $\left(10 \mathrm{~cm}^{-3}\right)$ during 12:00-14:00 UT.

Figure 7 shows H-component magnetograms from IMAGE Svalbard stations for the interval 08:00-16:00 UT when these stations swept through the 11:00-19:00 MLT sector. Times of ground-satellite conjunctions at station $\mathrm{Ny}$

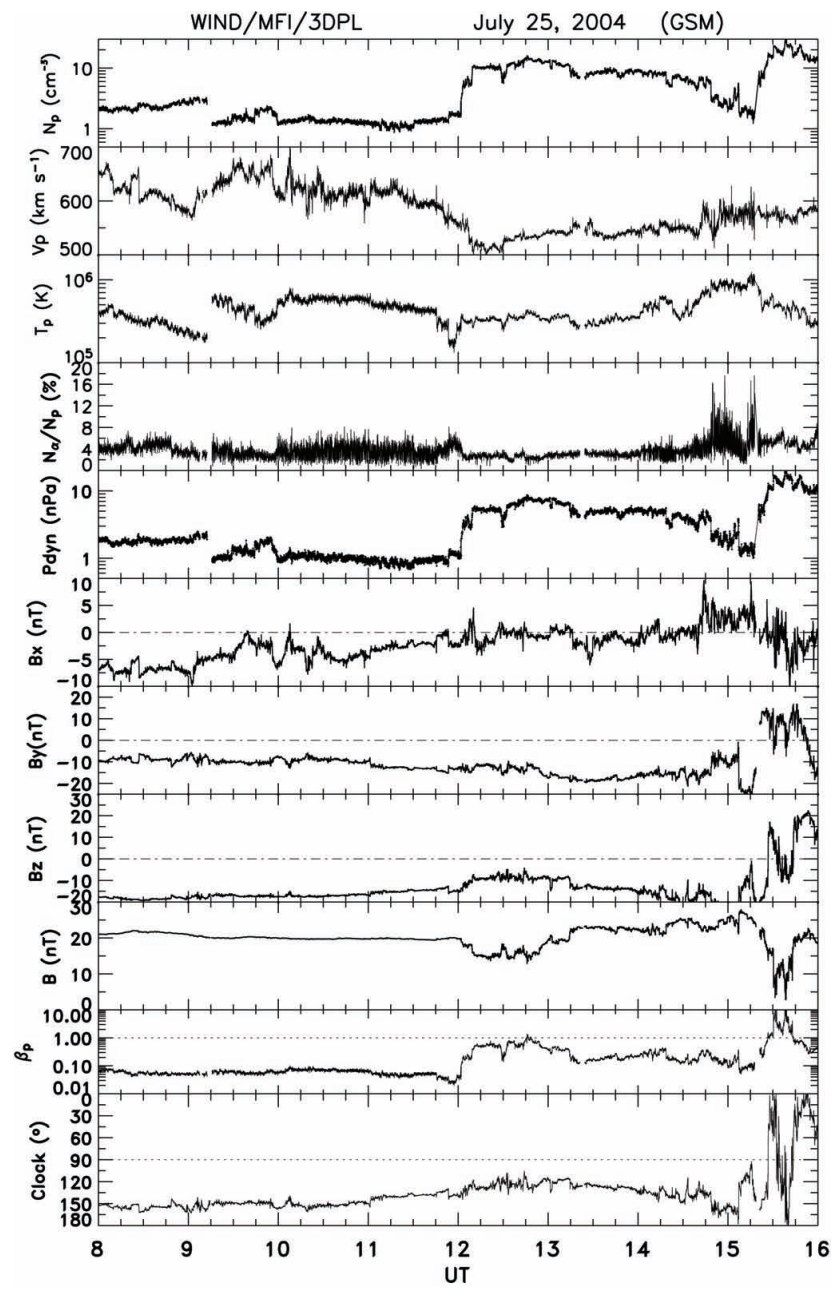

Fig. 6. Interplanetary plasma and field data obtained from spacecraft Wind during the interval 08:00-16:00 UT on 25 July 2004. Same format as in Fig. 2.

Ålesund (NAL) are marked by vertical guidelines at 10:43 and 12:24 UT. At these times satellite DMSP F13 observed cross-track ion drifts and particle precipitation above Svalbard during polar cap crossings from dusk to dawn. These ground-satellite conjunctions allow us to relate the ground magnetic deflection events to the configurations of plasma convection, precipitation and Birkeland currents in the dusk sector of the polar cap.

Increasing negative $\mathrm{H}$-component deflection is observed at all three stations during the interval 08:00-14:00 UT (11:0017:00 MLT). Superimposed on this general trend is a series short-lived (10-15 min) negative deflections. We shall focus on the two deflection events marked by vertical guidelines that appeared when ground-satellite conjunctions took place. The conjunctions at 10:43 and 12:24 UT occurred in the maximum and recovery phases, respectively, of the two similar deflection events. 


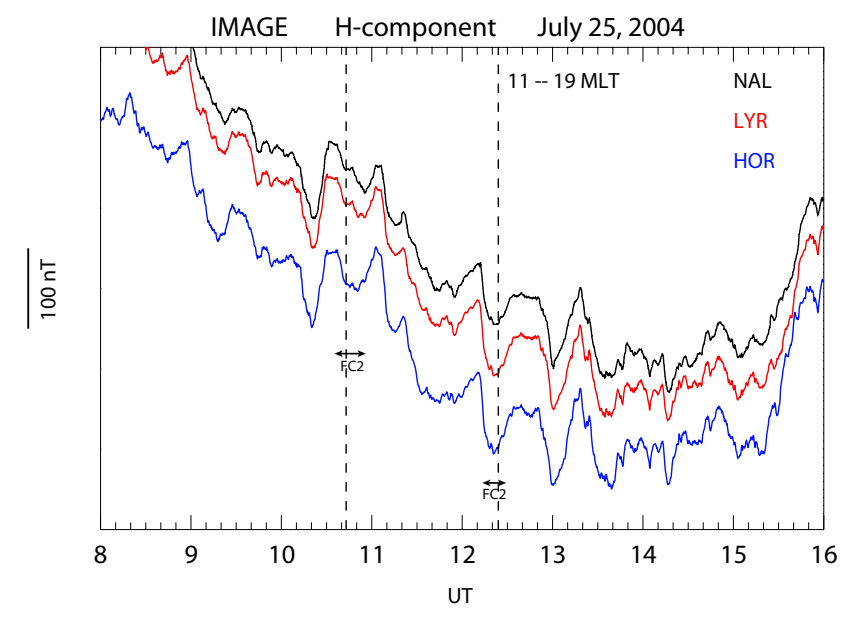

Fig. 7. H-component magnetic deflections from the Image Svalbard chain of stations Ny Ålesund (NAL; $76^{\circ}$ MLAT; black trace), Longyearbyen (LYR; $75^{\circ}$ MLAT; red), and Hornsund (HOR; $74^{\circ}$ MLAT; blue) for the interval 08:00-16:00 UT when the stations swept through the 11:00-19:00 MLT sector. Vertical guidelines at 10:43 and 12:24 UT mark passages of satellite DMSP F13 in the vicinity of Svalbard; i.e., the times of the closest approach to station NAL. The two intervals of corresponding FC 2 flow channel activation have been marked.

The magnetic deflection event centered at 12:20 UT shows a sharp onset at 12:13 UT (occurring simultaneously at all three stations spanning the latitude range $74-76^{\circ}$ MLAT) and recovery from 12:23 UT onwards. The amplitude of this deflection event is somewhat larger $(\sim 100 \mathrm{nT})$ than the 10:43 UT event ( $\sim 50 \mathrm{nT})$.

By comparison with the satellite data obtained during these DMSP F13-Svalbard conjunctions we shall be able to determine the correspondence between the magnetic deflection and the ion drift events and thereby to estimate the duration of the two flow channel events (FC 2), as indicated in the figure.

We note that the positive $\mathrm{H}$-deflections appearing ahead of the negative excursions most likely reflect the FC 1 flow channel (see the illustration in Fig. 1). The association between the FC 1 magnetic signature and poleward moving auroral forms (PMAFs) has been documented in Sandholt et al. (1990) and Øieroset et al. (1997).

Figure 8 shows an overview of the observation geometry on 25 July with tracks of satellite F13 across the Northern Hemisphere polar cap (dusk-to-dawn) during the intervals 10:36-10:54 UT (top panel) and 12:20-12:36 UT. The two ground-satellite conjunctions occurred at 10:43 (top) and 12:24 UT (bottom). The locations of two ground stations on Svalbard (NAL: $76^{\circ}$ MLAT; HOR: $74^{\circ}$ MLAT) at 10:43 (top) and 12:24 UT (bottom) have been marked. The two times (also marked in Fig. 7) correspond to the closest approaches to ground station NAL in the two cases. The satellite crossing of flow channel FC 2 and Birkeland current regimes C1
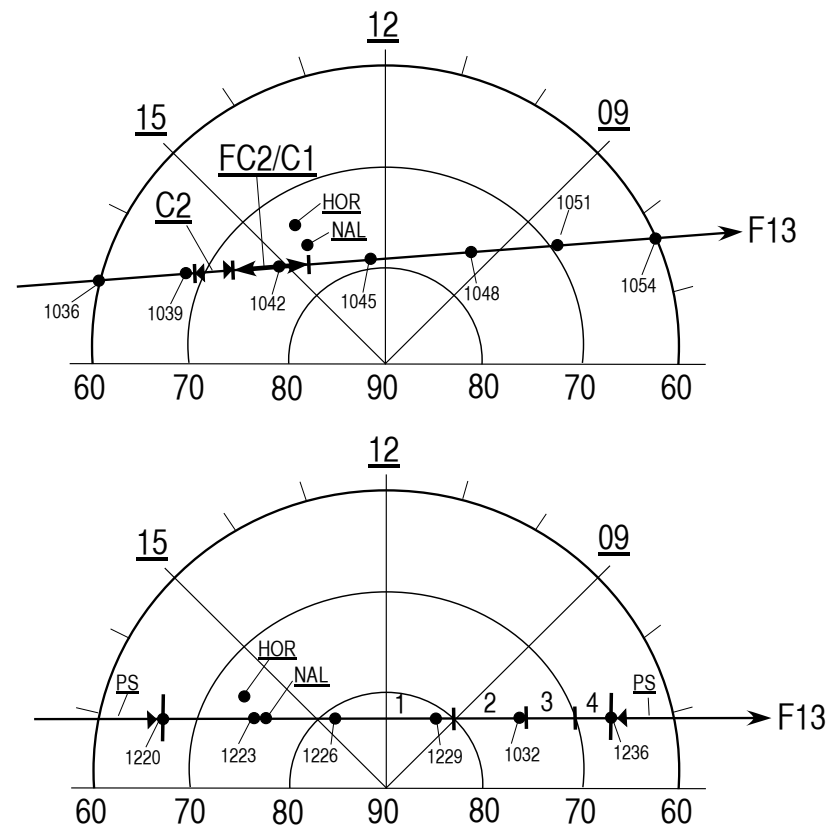

Fig. 8. The observation geometry showing tracks of satellites DMSP F13 across the polar cap from dusk to dawn during the intervals 10:36-10:54 UT (top panel) and 12:20-12:36 UT (bottom). The locations of two ground stations on Svalbard (NAL: $76^{\circ}$ MLAT; HOR: $74^{\circ}$ MLAT) at 10:43 UT (top) and 12:24 UT (bottom) are marked by dots. These times correspond to the closest approaches of DMSP F13 to station NAL. The plasma flow feature (FC 2) and Birkeland current regimes C1 (inward-directed) and C2 (outwarddirected) are marked along the track in the top panel. Satellite entry into the polar cap (plasma sheet-polar rain preciptation boundary) at 12:20 UT and exit at 12:36 UT have been marked in the bottom panel. The coordinate system is MLT/MLAT.

(inward-directed) and C2 (outward-directed) during the interval 10:39-10:43 UT are indicated along the track in the top panel.

In the bottom panel we marked the satellite entry into the polar cap on the dusk side at 12:20 UT and the exit on the dawn side at 12:36 UT. The satellite crossed over ground station NAL at 12:23-12:24 UT. We shall focus on this ground-satellite conjunction. Four different precipitationconvection-Birkeland current regimes are marked on the dawn side of the polar cap.

Figure 9 shows cross-track ion drifts during the same dusk-dawn crossings of the polar cap shown in Fig. 8. The upper panel shows the presence of flow channel FC 2 (enhanced antisunward convection) in the 14:30-16:00/71$76^{\circ}$ MLT/MLAT sector during the interval 10:40-10:43 UT (see the V-shaped flow profile). This is within the time interval of a $15 \mathrm{~min}$ long magnetic deflection event as marked by the first vertical guideline in Fig. 7. The latitude of maximum flow speed $(1.2 \mathrm{~km} / \mathrm{s})$, i.e. the most intense Hall current, is at $72-73^{\circ}$ MLAT. This is consistent with the observation of maximum negative $\mathrm{H}$-component magnetic deflection 

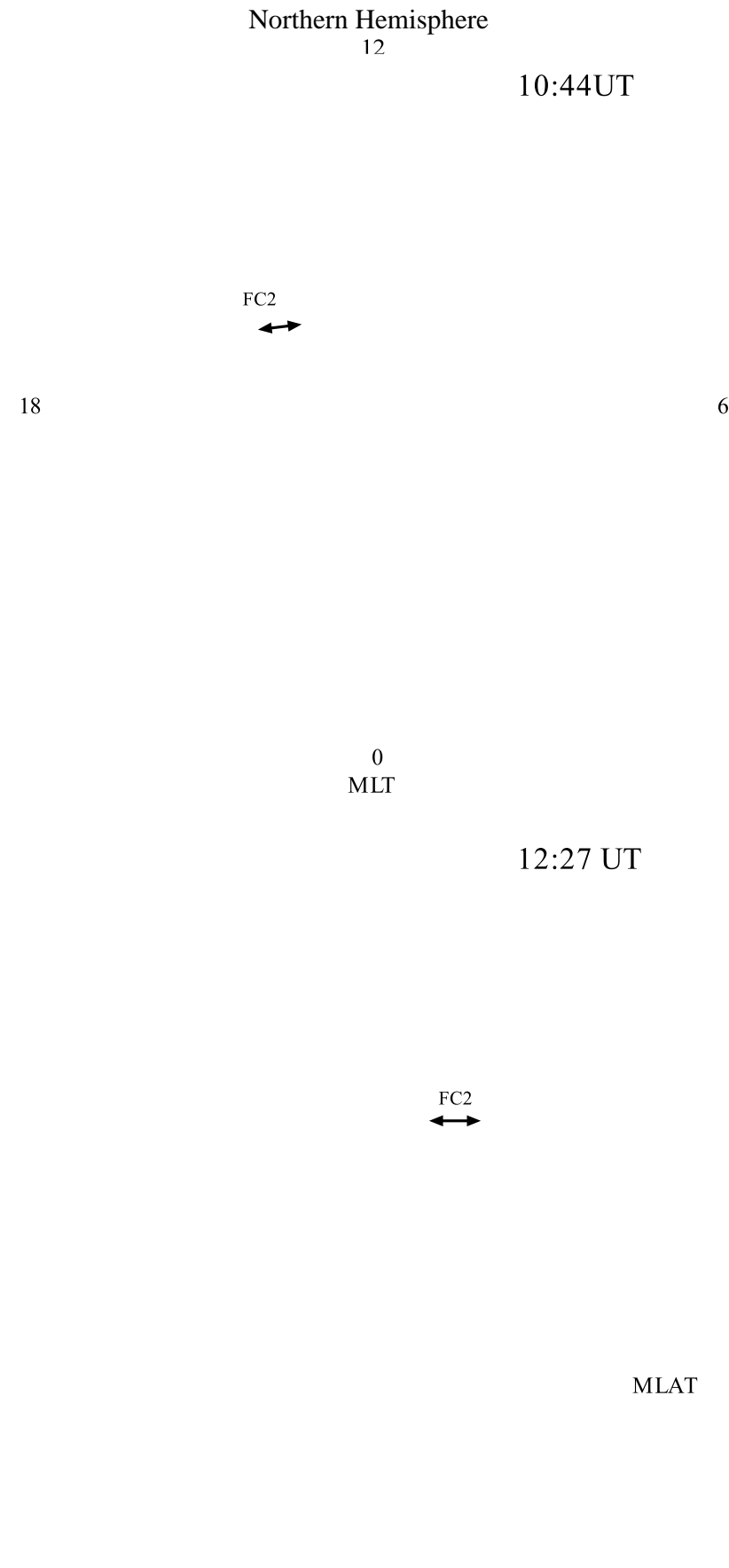

Fig. 9. Cross-track ion drifts along two consecutive satellite passes across the polar cap from dusk to dawn in the Northern Hemisphere centered at 10:44 UT (top panel) and 12:27 UT (bottom) obtained by satellite DMSP F13. The coordinate system is MLT/MLAT. Latitude circles at $50-80^{\circ}$ MLAT have been drawn. The drift scale is shown in a later figure. (Blue and yellow mark "undetermined" and "caution", respectively).

(compared to the deflections at the higher-latitude stations LYR and NAL) at this time occurring at the southernmost station HOR (see Fig. 7).

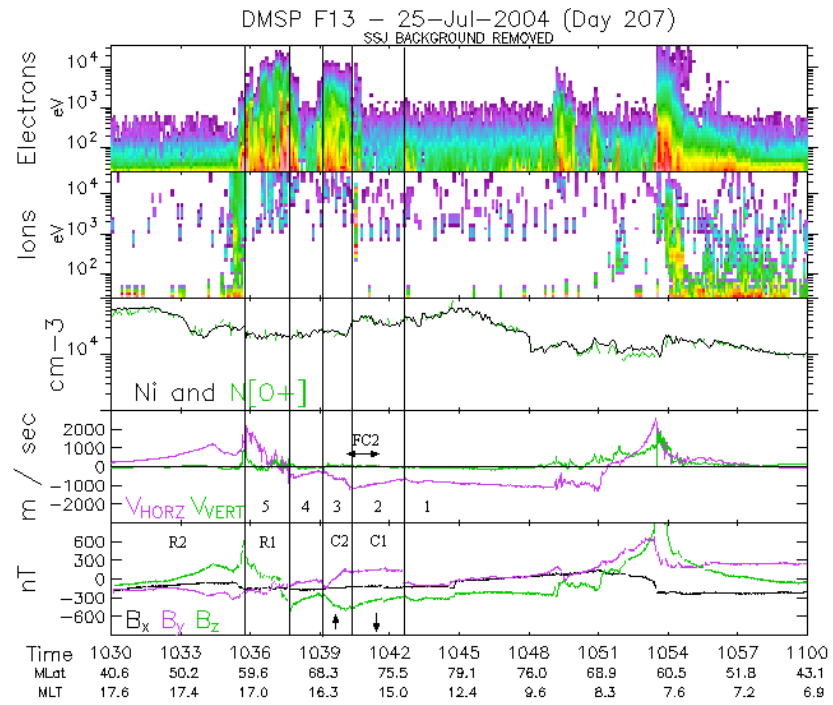

Fig. 10. DMSP F13 data obtained during the interval 10:3011:00 UT on 25 July 2004. Panels from top to bottom shows (i) electron precipitation spectrogram (particle flux versus energy and time), (ii) ion precipitation flux, (iii) ion densities, (iv) cross track (violet trace) and vertical ion drifts, and (v) magnetic deflection components $B_{\mathrm{X}}, B_{\mathrm{y}}$, and $B_{\mathrm{Z}}$. Five regimes of different convection/precipitation/Birkeland current configuration have been delimited by vertical guidelines.

The lower panel shows the cross-track ion drifts during the pass centered at 12:27 UT. The satellite reached the latitude of ground station NAL (the closest station) at 12:2312:24 UT (see Fig. 8). At this time the H-component trace at NAL (and LYR and HOR) had started to recover after a negative deflection event (see Fig. 7).

This pass is characterized by the following flow features in the polar cap: (i) the total absence of FC 2 flow channel on the dusk side (the background level of antisunward flow speeds within $70-80 \mathrm{MLAT}$ is $\leq 0.4 \mathrm{~km} / \mathrm{s}$ ); (ii) the presence of flow channel FC 2 on the dawn side (see the V-shaped cross-track drift profile).

In Fig. 10 we shall focus on electron precipitation (top panel), cross track ion drift (violet trace in third panel), and the $B_{\mathrm{z}}$ component (east-west; green trace in bottom panel) magnetic deflection. The satellite track is that shown in the top panels of Figs. 8 and 9.

We subdivided the precipitation/convection/Birkeland current configuration in the dusk side traversal of the oval/polar cap in the following regimes: (1) central polar cap with antisunward convection and polar rain precipitation; (2) flow channel FC 2 and polar rain precipitation, inward-directed C1 Birkeland current (positive $B_{\mathrm{z}}$-gradient); (3) plasma sheet, antisunward convection, outward-directed C2 Birkeland current (negative $B_{\mathrm{Z}}$-gradient); (4) reduced plasma sheet, slow antisunward convection; (5) plasma sheet, sunward convection, and outward-directed R1 Birkeland current (negative $B_{\mathrm{z}}$-gradient). 


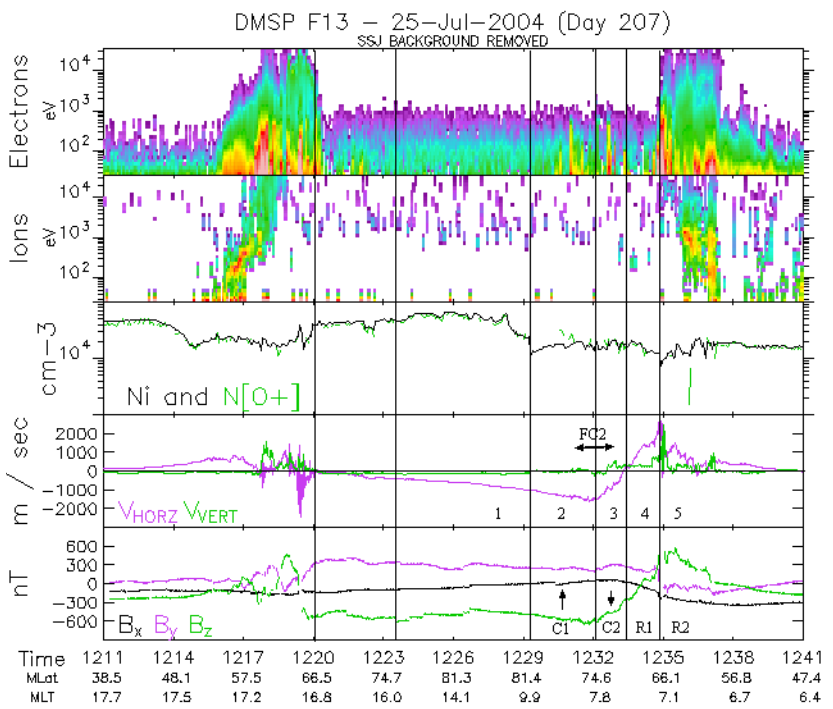

Fig. 11. DMSP F13 data obtained during the interval 12:1112:41 UT on 25 July 2004. Panels from top to bottom shows (i) electron precipitation spectrogram (particle flux versus energy and time), (ii) ion precipitation flux, (iii) ion densities, (iv) cross track (violet trace) and vertical ion drifts, and (v) magnetic deflection components $B_{\mathrm{X}}, B_{\mathrm{y}}$, and $B_{\mathrm{Z}}$. Same format as in Fig. 10 .

Figure 11 shows the cross-track ion drift data (panel 4) obtained during the dusk-dawn crossing of the polar cap during the interval 12:20-12:35 UT in the context of particle precipitation (panels 1 and 2) and magnetic deflections (bottom panel). The location of the poleward boundary of plasma sheet precipitation (entry into the polar cap on the dusk side) at 12:20 UT (66.5 $\left.5^{\circ} \mathrm{MLAT} / 16.8 \mathrm{MLT}\right)$ and polar cap exit (on the dawn side) at 12:35 UT (66.1 ${ }^{\circ}$ MLAT/7.1 MLT) are marked by the first and last vertical guidelines, respectively. The closest approach to ground station NAL ( $76^{\circ}$ MLAT) occurred at 12:24 UT and is marked by the second vertical guideline.

Flow channel FC $2\left(\mathrm{NH}-\mathrm{dusk} / B_{\mathrm{y}}<0\right)$ and the associated Birkeland current system $(\mathrm{C} 1-\mathrm{C} 2)$ are clearly absent on the dusk side at this time. The level of antisunward convection on the poleward side of the oval aurora (plasma sheet precipitation) is very weak $(\sim 0.3 \mathrm{~km} / \mathrm{s})$. This is the state of background convection in the duskside polar cap corresponding to the decreasing phase of the magnetic deflection event detected by IMAGE from 12:23 UT onwards (see Fig. 7). Thus in this case we may infer the duration of the flow channel event to be $10 \min (12: 13-12: 23$ UT).

On the dawn side we notice the following regimes (delimited by vertical guidelines): (1) central polar cap with antisunward convection $\left(V_{\mathrm{HORZ}}<1 \mathrm{~km} / \mathrm{s}\right)$ and polar rain precipitation; (2) enhanced antisunward convection $\left(V_{\text {HORZ }}>\right.$ $1 \mathrm{~km} / \mathrm{s}$ ) and outward-directed C1 Birkeland current (negative $B_{\mathrm{Z}}$-gradient); (3) antisunward convection and inwarddirected C2 Birkeland current (positive $B_{\mathrm{z}}$-gradient); (4) sun- ward convection and inward-directed R1 Birkeland current (positive $B_{\mathrm{z}}$-gradient); (5) plasma sheet precipitation and outward-directed R2 Birkeland current (negative $B_{Z^{-}}$ gradient).

Regimes 2 and 3 (poleward part where $V_{i} \geq 1 \mathrm{~km} / \mathrm{s}$ ) on the dawn side do satisfy our criteria for an FC 2 flow channel (marked by horizontal double-arrowed line in panel 4).

\section{Summary and conclusions}

We reported ion drift features (flow channel FC 2) and associated ground magnetic deflections in the postnoon-dusk sector of the Northern Hemisphere polar cap during Earth passage of two ICMEs in 2004. The ground-satellite conjunctions on 25 July allow us to study the temporal behaviour of the convection channel events. Thus, the flow channel variant we study here is that which appears on the dusk side of the polar cap in the Northern Hemisphere during IMF $B_{\mathrm{y}}<0$ conditions $\left(\mathrm{NH}\right.$-dusk $\left./ B_{\mathrm{y}}<0\right)$. We note that during the interval of our observations on 25 July, when the clock angle of the ICME magnetic field changed slowly within the range $135-150^{\circ}$ and $\left|B_{\mathrm{z}} / B_{\mathrm{y}}\right|>1$ (see Fig. 6), flow channel FC 2 was observed on both sides (at different times) of the polar cap. Thus, FC 2 is identified on the dusk side in the 10:44 UT pass while it is seen on the dawn side in the 12:27 UT pass of satellite F13 (see Fig. 9). The full documentation of the dual mode (dawn+dusk) of FC 2 during intervals of strongly south $\left(B_{\mathrm{Z}}\right.$-dominated) IMF orientation is the topic of a separate paper in preparation. In the present study we shall focus on the dusk-side events where the ground-satellite conjunctions occurred.

In case 1 (10 January) we identify the ground magnetic signature of a NH-dusk $/ B_{\mathrm{y}}<0$ flow channel detected by SuperDARN radars when the flow enhancements were "directly driven" by southward turnings of the magnetic field in the ICME (see Fig. 3).

In case 2 ( 25 July) we documented the ion drift from satellite DMSP F13 corresponding to two different phases of two different ground magnetic deflection events as detected from three IMAGE chain stations on Svalbard covering the latitude range $74-76^{\circ}$ MLAT in the 12:00-18:00 MLT sector. This case is characterized by a series of magnetic deflection/convection events appearing during a long (several hours) interval of quasi-steady ICME magnetic field. This is the "spontaneous response".

The ground-satellite conjunction at 10:43 UT occurred in the maximum phase of a magnetic deflection event (marked by vertical guideline in Fig. 7). The satellite data for this case show all the classical elements of the FC 2 flow channel of type $\mathrm{NH}$-dusk $/ B_{\mathrm{y}}<0$ : (i) antisunward convection maximizing at a speed $(1.2 \mathrm{~km} / \mathrm{s})$ above the level of ion drift in the central polar cap, as detected by DMSP F13 in the 71\%16.5$76 \% 15$ MLAT/MLT sector within which the potential drop is $35 \mathrm{kV}$ ( $25 \%$ of the total cross polar cap potential (CPCP) 
as inferred from the along the track $\boldsymbol{E}$-field component integrated along the track), (ii) the flow channel is observed in the regime of polar rain precipitation, poleward of the poleward boundary of plasma sheet precipitation (regime 2 in Fig. 10), (iii) the flow channel is associated with a system of downward (C1) and upward-directed (C2) Birkeland currents located poleward of the traditional R1-R2 currents (regimes 2 and 3 in Fig. 10).

The good correlation observed between the parameters $V_{\mathrm{HORZ}}$ and $B_{\mathrm{Z}}$ in this case (Fig. 10) confirms the current continuity relation $j_{\|}=-\Sigma_{P} \nabla \boldsymbol{E}$ (Smiddy et al., 1980). This demonstrates that flow channel FC 2 is formed by the ionospheric Pedersen current closure of Birkeland currents C1C2. The $\mathrm{C} 1-\mathrm{C} 2$ Birkeland current configurations corresponding to the different FC 2 flow channels appearing during IMF $B_{\mathrm{y}}<0$ conditions are indicated in Sandholt et al. (2010).

The ground-satellite conjunction at 12:24 UT occurred in the recovery phase of a magnetic deflection event (see Fig. 7). The satellite data for this case show the total absence of flow channel FC 2. Correspondingly, only a background convection at a speed of $\sim 0.3 \mathrm{~km} / \mathrm{s}$ is recorded at this time (see Fig. 11).

From these two ground-satellite conjunctions we conclude that the ion drift in flow channel FC 2 increases and decreases in concert with the $\mathrm{H}$-component deflections recorded on the ground underneath the ionospheric flow. This is reasonable since the magnetic deflection reflects the ionospheric Hall current (Fukushima, 1969) driven by the ionospheric $\boldsymbol{E}$-field $\left(\boldsymbol{J}_{\mathbf{H}}=\Sigma_{\mathrm{H}} \boldsymbol{B} \times \boldsymbol{E} / B\right)$. In this case the ionospheric conductivity in the polar cap is due to ionization by sunlight (sunlit ionosphere). The ground magnetic deflections are recorded from polar cap stations (HOR-LYR-NAL) in the $74-76^{\circ}$ MLAT range while the poleward boundary of plasma sheet precipitation is identified at $66.5^{\circ}$ MLAT in the 12:2212:24 UT case.

We conclude that in the 25 July 2004 case the ion drift in flow channel FC $2\left(\mathrm{NH}-\right.$ dusk $\left./ B_{\mathrm{y}}<0\right)$ is pulsed in a similar way as the ground magnetic deflection events. The ion drift ( $\boldsymbol{E}$-field) variability is directly observed from DMSP F13 in our case: $V i_{\mathrm{FC} 2}(10: 40 \mathrm{UT})=1.2 \mathrm{~km} / \mathrm{s} ; V i_{\mathrm{FC} 2}$ $(12: 24 \mathrm{UT})=0.3 \mathrm{~km} / \mathrm{s}$. These two times correspond to the increasing and decreasing phases of two different magnetic deflection (Hall current) events in the event series on 25 July 2004. Based on the assumption that the sharp onset of the $\mathrm{H}$ component deflection at 12:13 UT is driven by an ion drift enhancement (compare case 1) and the observed recovery from 12:23 UT (when a slow background ion drift of $0.3 \mathrm{~km} / \mathrm{s}$ was observed), we infer the duration of the convection event to be $\sim 10 \mathrm{~min}$. This event duration seems to be typical of the 25 July event series. From the ground magnetic data and the satellite ion drift observations we infer these convection enhancements to be superimposed on a quasi-steady background convection pattern.
The 5-10-min-long FC 2 convection channel events documented here and in Sandholt et al. (2010) are attributed to momentum transfer from the high-latitude and flank boundary layers, on the downstream side of the cusp, via the $\mathrm{C} 1-$ $\mathrm{C} 2$ Birkeland currents (see regimes 2 and 3 in Fig. 10), associated with flux transfer events. These convection events represent an important spatial-temporal structure of solar wind-magnetosphere-ionosphere coupling which is not included in present large statistical studies (Ruohoniemi and Greenwald, 2005) and in conceptual models (Cowley and Lockwood, 1992) of plasma convection which generally emphasize newly-opened magnetic field lines as agents of momentum and energy transfer to the ionsophere. During $B_{\mathrm{y}^{-}}$ dominated $\left(\left|B_{\mathrm{y}} / B_{\mathrm{z}}\right|>1\right)$ IMF conditions (see our 10 January case) the FC 2 flow feature contributes to enhancing the dawn-dusk convection asymmetry in the antisunward direction (beyond the cusp region). During $B_{\mathrm{Z}}$-dominated $\left(\left|B_{\mathrm{y}} / B_{\mathrm{z}}\right|<1\right)$ IMF conditions (see our 25 July case) the antisunward flow speeds are enhanced at both the dawn and dusk side boundaries of the polar cap with respect to the flow observed in the central polar cap (see Fig. 10). The duration of the ionospheric flow events documented here is near the lower limit of previous estimates of the duration of dayside flow events, extending from 5 to $25 \mathrm{~min}$ (Lockwood et al., 1990; Greenwald et al., 1999).

Finally we make a brief comment on the importance of the FC 2 flow channel feature by placing it in the context of solar wind - magnetosphere - ionosphere coupling. Figure 12 illustrates the FC 2 current loop consisting of $\mathrm{C} 1-$ C2 Birkeland currents (the HCC-LCC currents of Taguchi et al., 1993) with their ionospheric Pedersen current closure and the connection to the cusp dynamo current at high altitudes (on the downstream side of the cusp). The FC 2 current loop is placed in the context of the R1-R2 Birkeland currents with their closure currents in the magnetosphere (ring current and cusp dynamo current) and ionosphere, as described by Tanaka et al. (2010) (see their Fig. 20). The associated eastward- and westward-directed ionospheric electrojet currents on the western (EEJ) and eastern (WEJ) sides of the Harang discontinuity are also marked. The FC 2 current loop we added to the Tanaka et al. system is similar to the Southwood (1987) type of current system. The difference is the context of application. While the Southwood (1987) system was applied to momentum transfer on "newly open" field lines (flow channel FC 1; pulsed ionospheric flows; PIFs), our FC 2 current loop is applied in the regime of "old open" field lines (embedded in polar rain precipitation) on the downstream side of the cusp. Thus, FC 2 is a manifestation of effective momentum transfer in a later stage of the evolution of open magnetic flux (time since reconnection $\sim 10-20 \mathrm{~min}$ ) in the convection cycle (see Fig. 1). The transition between the two phases in this evolution (FC 1-FC 2 activations) is illustrated by the magnetic signatures (positive-negative $\mathrm{H}$-deflections) shown in Figs. 3 and 7. 


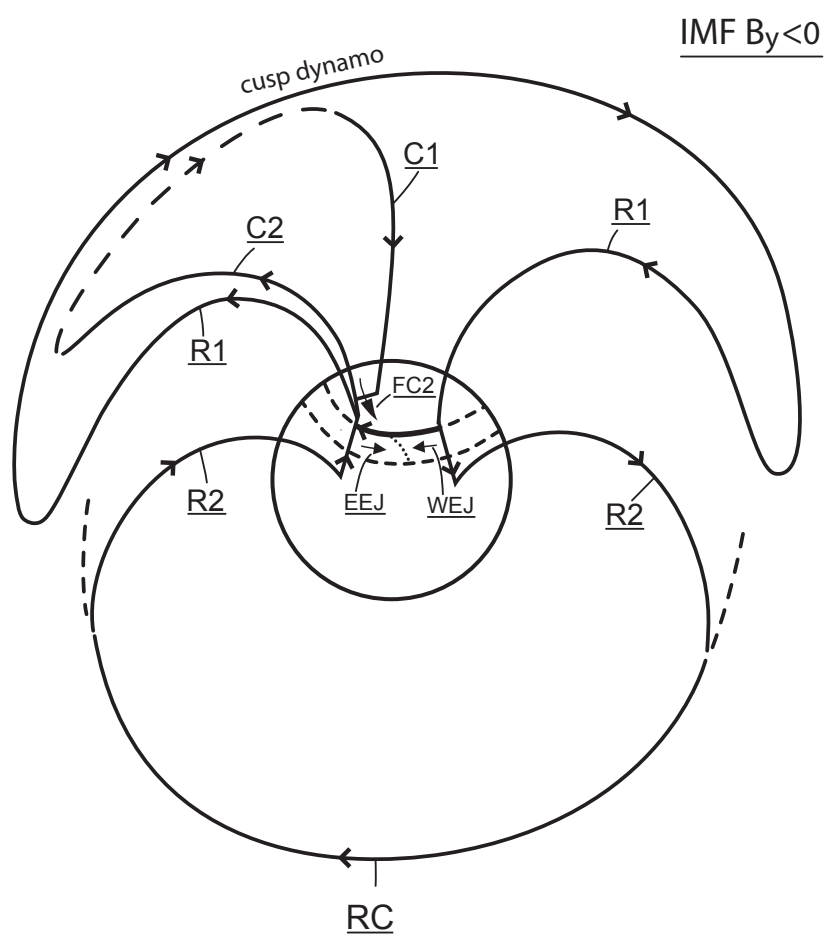

Fig. 12. Schematic illustration of current loops in the magnetosphere-ionosophere system adapted after Tanaka et al. (2010). Birkeland current systems (R1-R2 and C1-C2), magnetospheric ring current (RC), cusp dynamo current, and ionospheric closure currents have been marked. The FC 2 current loop (cusp dynamo current - C1-C2 Birkeland currents - ionospheric Pedersen current) is the topic of this paper. The perspective is from the magnetotail towards the Earth (circle). The auroral oval boundaries are marked by the two dashed curved lines. See text for details.

In this article we documented the temporal behaviour (pulsed nature) of the FC 2 current loop via the observation of the ground magnetic signature of the ionospheric Hall currents relating to flow channel FC 2. The FC 2 ion drift and the $\mathrm{C} 1-\mathrm{C} 2$ Birkeland currents were documented by data from spacecraft DMSP F13.

Acknowledgements. We kindly thank Gordon Wilson and Kevin Martin for providing us with DMSP data. Ground magnetograms from the Svalbard IMAGE chain of ground stations were obtained from http://www.geo.fmi.fi/image. Thanks to Ari Viljanen and Truls Lynne Hansen for operating the IMAGE magnetometer chain on Svalbard. SuperDARN convection plots were obtained from http://superdarn.jhuapl.edu. Work at University of Oslo is supported by the Norwegian Research Council (NFR). Work at UNH is supported by NASA Wind grant NNX10AQ29G.

Topcial Editor I. A. Daglis thanks A. Rodger and R. Walker for their help in evaluating this paper.

\section{References}

Burlaga, L. F., Sittler, E., Mariani, F., and Schwenn, R.: Magnetic loop behind an interplanetary shock: Voyager, Helios, and IMP8 observations, J. Geophys. Res., 86, 6673-6684, 1981.

Cowley, S. W. H. and Lockwood, M.: Excitation and decay of solar wind-driven flows in the magnetosphere-ionosphere system, Ann. Geophys., 10, 103-115, 1992.

Crooker, N., Siscoe, C., Russell, G., and Smith, E. E.: Factors controlling degree of correlation between ISEE 1 and ISEE 3 interplanetary magnetic field measurements, J. Geophys. Res., 87(A4), 2224-2230, 1982.

Farrugia, C. J., Scudder, J. D., Freeman, M. P., Janoo, L., Lu, G., Quinn, J. M., Arnoldy, R. L., and Torbert, R. B.: Geoeffectiveness of three Wind magnetic clouds: A comparative study, J. Geophys. Res., 103, 17261-17278, 1998.

Farrugia, C. J., Lund, E. J., Sandholt, P. E., Wild, J. A., Cowley, S. W. H., Balogh, A., Mouikis, C., Mbius, E., Dunlop, M. W., Bosqued, J.-M., Carlson, C. W., Parks, G. K., Cerisier, J.C., Kelly, J. D., Sauvaud, J.-A., and Rème, H.: Pulsed flows at the high-altitude cusp poleward boundary, and associated ionospheric convection and particle signatures, during a Cluster FAST - SuperDARN - Søndrestrøm conjunction under a southwest IMF, Ann. Geophys., 22, 2891-2905, doi:10.5194/angeo22-2891-2004, 2004.

Farrugia, C. J., Matsui, H., Kucharek, H., et al.: Interplanetary coronal mass ejection and ambient interplanetary magnetic field correlations during the Sun-Earth connection events of October-November 2003, J. Geophys. Res., 110, A09S13, doi:10.1029/2004JA010968, 2005.

Fukushima, N.: Equivalence in ground geomagnetic effect of Chapman-Vestine and Birkeland-Alfven electric current systems for polar magnetic storms, Rep. Ionos. Space Res. Jap., 23, 219 227, 1969.

Greenwald, R. A., Bristow, W. A., Sofko, G. J., Senior, C., Cerisier, J.-C., and Szabo, A.: Super Dual Auroral Radar Network radar imaging of dayside high-latitude convection under northward interplanetary magnetic field: Toward resolving the distorted twocell versus multicell controversy, J. Geophys. Res., 100(A10), 19661-19674, 1995.

Greenwald, R. A., Ruohoniemi, J. M., Baker, K., Bristow, W. A., Sofko, G. J., Villain, J. P., Lester, M., and Slavin, J.: Convective response to a transient increase in dayside reconnection, J. Geophys. Res., 104(A5), 10007-10015, 1999.

Greenwald, R. A., Shepherd, S. G., Sotirelis, T. S., Ruohoniemi, J. M., and Barnes, R. J.: Dawn and dusk sector comparisons of small-scale irregularities, convection, and particle precipitation in the high-latitude ionosphere, J. Geophys. Res., 107(A9), 1241, doi:10.1029/2001JA000158, 2002.

Hairston, M. R., Heelis, R. A., and Rich, F. J.: Analysis of the ionospheric cross polar cap potential using DMSP data during the National Space Weather Program study period, J. Geophys. Res., 103, 26337-26347, 1998.

Lockwood, M., Cowley, S. W. H., Sandholt, P. E., and Lepping, R. E.: The ionospheric signature of flux transfer events and solar wind dynamic pressure changes, J. Geophys. Res., 95, 1711317135, 1990.

Lopez, R. E.: Solar cycle invariance in solar wind proton temperature relationships, J. Geophys. Res., 92(A10), 11189-11194, 1987. 
Lopez, R. E. and Freeman, J. W.: Solar wind proton temperaturevelocity relationship, J. Geophys. Res., 91, 1701-1705, 1986.

Øieroset, M., Sandholt, P. E., Luhr, H., Denig, W., and Moretto, T.: Auroral and geomagnetic events at cusp/mantle latitudes in the prenoon sector during positive IMF $B_{y}$ conditions: Signatures of pulsed magnetopause reconnection, J. Geophys. Res., 102, A4, doi:10.1029/96JA03716, 1997.

Pinnock, M., Rodger, A. S., Dudeney, J. R., Baker, K. B., Greenwald, R. A., and Greenspan, M.: Observations of an enhanced convection channel in the cusp ionosphere, J. Geophys. Res., 98, 3767-3776, 1993.

Provan, G., Yeoman, T. K., and Cowley, S. W. H.: The influence of the IMF $B_{y}$ component on the location of pulsed flows in the dayside ionosphere observed by an HF radar, Geophys. Res. Lett., 26, 4, doi:10.1029/1999GL900009, 1999.

Richardson, J. and Paularena, K.: Plasma and magnetic field correlations in the solar wind, J. Geophys. Res., 106(A1), 239-251, 2001.

Ruohoniemi, J. M. and Baker, K. B.: Large-scale imaging of highlatitude convection with Super Dual Auroral Radar Network HF radar observations, J. Geophys. Res., 103, 20797-20811, 1998.

Ruohoniemi, J. M. and Greenwald, R. A.: Dependencies of high-latitude plasma convection: Consideration of interplanetary magnetic field, season, and universal time factors in statistical patterns, J. Geophys. Res., 110, A09204, doi:10.1029/2004JA010815, 2005.

Sandholt, P. E. and Farrugia, C. J.: Spatiotemporal structure of the reconnecting magnetosphere under $B_{y}$-dominated interplanetary magnetic cloud conditions, J. Geophys. Res., 111, A10209, doi:10.1029/2005JA011514, 2006.
Sandholt, P. E. and Farrugia, C. J.: Plasma flow channels at the dawn/dusk polar cap boundaries: momentum transfer on old open field lines and the roles of IMF $B_{\mathrm{y}}$ and conductivity gradients, Ann. Geophys., 27, 1527-1554, doi:10.5194/angeo-271527-2009, 2009.

Sandholt, P. E., Lockwood, M., Oguti, T., Cowley, S. W. H., Freeman, K. S. C., Lybekk, B., Egeland, A., and Willis, D. M.: Midday auroral breakup events and related energy and momentum transfer from the magnetosheath, J. Geophys. Res., 95, 10391060, 1990.

Sandholt, P. E., Andalsvik, Y., and Farrugia, C. J.: Polar cap convection/precipitation states during Earth passage of two ICMEs at solar minimum, Ann. Geophys., 28, 1023-1042, doi:10.5194/angeo-28-1023-2010, 2010.

Smiddy, M., Burke, W. J., Kelley, M. C., Saflekos, N. A., Gussenhoven, M. S., Hardy, D. A., and Rich, F. J.: Effects of highlatitude conductivity on observed convection electric fields and Birkeland currents, J. Geophys. Res., 85, 6811-6818, 1980.

Southwood, D. J.: The ionospheric signature of flux transfer events, J. Geophys. Res., 92, 3207-3213, 1987.

Taguchi, S., Sugiura, M., Winningham, J. D., and Slavin, J.: Characterization of the IMF $B_{y}$-dependent field-aligned currents in the cleft region based on DE 2 observations, J. Geophys. Res., 98, 1393-1407, 1993.

Tanaka, T., Nakamizo, A., Yoshikawa, A., Fujita, S., Shinagawa, H., Shimazu, H., Kikuchi, T., and Hashimoto, K. K.: Substorm convection and current system deduced from the global simulation, J. Geophys. Res., 115, A05220, doi:10.1029/2009JA014676, 2010. 